\title{
An Examination of the Impacts of Volunteering and Community Contribution at a Community Festival Through the Lens of the Five Ways to Wellbeing
}

\author{
E. Coren ${ }^{1}$ (D) J. Phillips ${ }^{2}$ D . J. Moore ${ }^{1}$ (D) T. Brownett ${ }^{3} \cdot$ L. Whitfield ${ }^{2}$
}

Received: 10 September 2020 / Accepted: 1 November 2021 / Published online: 29 November 2021

(c) The Author(s), under exclusive licence to Springer Nature Switzerland AG 2021

\begin{abstract}
The aim of this study was to examine the perceptions, motivations and wellbeing impacts for volunteers and contributors to Broadstairs Folk Week. The study utilised questionnaires with a mix of quantitative and qualitative measures, within a single cohort $(n=152)$. Analysis was conducted using IBM SPSS 24 to produce descriptive statistics, and cross-tabulations were used to interrogate key variables. NVivo 11 software was used to analyse qualitative comments. A thematic analysis (thematic development) approach further identified codes and themes that fitted well with the Five Ways to Wellbeing (Aked, J., Marks, N., Cordon, C. and Thompson, S. (2008). Five ways to wellbeing: a report presented to the Foresight Project on communicating the evidence base for improving people's well-being, New Economics Foundation. Retrieved from https://b.3cdn.net/nefoundation/8984c5089d5c2285ee_ t4m6bhqq5.pdf). Findings demonstrate that older-adult festival volunteers had a higher sense of subjective wellbeing prior to the festival than might ordinarily be expected in a similar group. Participants reported their sense of wellbeing increased during the festival. The Five Ways to Wellbeing model is suggested as a useful way to frame the results, linking a sense of 'connection' and 'giving' as participant motivators. This paper argues that festival volunteers derive personal benefits, including sense of connection and reciprocity, and access to resources with potential health and wellbeing benefits. This may be beneficial to the public health agenda of community development, reducing isolation and supporting healthy ageing.
\end{abstract}

Keywords Volunteering $\cdot$ Festival $\cdot$ Arts and Health $\cdot$ Wellbeing $\cdot$ Five ways to wellbeing

E. Coren

esther.coren@canterbury.ac.uk

Extended author information available on the last page of the article 


\section{Introduction}

Involvement in the arts and culture is a key component for both the overall health and wellbeing of society and the individuals within it (Royal Society for Public Health (RSPH), 2013). Along with supporting wellbeing, participation in the arts can increase self-confidence and inspire trust, tolerance and respect (Jensen, 2013). UK festivals are described as a "vital aspect of cultural life" offering opportunities for a range of audiences to engage with cultural events (Arts Council England, 2018 p.3).

Festivals have long been considered a way to celebrate community social identity, Biaett (2015) draws attention to community festivals as far back as $1600 \mathrm{CE}$, arguing that they created unity and supported shared values between individuals and groups. In defining community festivals, Falassi (1987) saw the social functioning of a festival as upholding a community's physical survival, ideology, history and identity. Falassi also discussed community festivals in relation to wellbeing, stating that they are a good way to give renewed vitality to the community. Getz $(1991,1997)$ describes festivals as a way to develop a community and encourage understanding between diverse groups, promoting community cultural development.

Research into community festivals has predominantly remained within the field of tourism and leisure studies, and evaluations have typically focused on the economic impact rather than potential health, social or community benefits (Arcodia \& Whitford, 2006; McQueen-Thomson et al., 2004). Matarasso (1996), however, briefly addressed festivals and social impacts by investigating the social impacts of Gaelic community festivals. He found the festivals contributed towards individual and personal development, social cohesion, community empowerment and self-determination, local image and identity, and health and wellbeing.

More recently research has expanded beyond the tourism and economic focus to show festivals can promote positive feelings towards oneself and others, as well as inspiring attendees to engage in new activities (Ballantyne et al., 2004). The importance of festivals is evident in the opportunity for individuals and groups to come together, to create shared experiences and to take time for themselves which contributes to their wellbeing (Yoo et al., 2013; Li \& Wood, 2014). Festivals can also promote social inclusion and diversity, accommodating people from marginalized groups (Gorman-Murray, 2009) through free or minimal ticket fees and the promotion and celebration of cultural heritage and integration (RSPH, 2013; Hassanli et al., 2020).

Later studies have looked at participatory community festivals, demonstrating the creation of social capital, feelings of belonging and sense of connectedness, community cohesiveness, happiness, community contentment, and a renewed excitement for shared community spaces (Brownett \& Evans, 2020; Sholihah et al., 2019). Acordia and Whitford (2006) described social capital as derived from cohesion and celebration, others have hypothesised that an optimal festival experience can give rise to bond and bridging capital described as 'Organic Festivity Theory' (Biaett, 2017, in Phillips and Wong, p.190). Biaett (2019, 
p250-251) in discussing a 'good leisure experience' argues that a combination of three attributes leading to 'organic festivity': incorporating Csikszentmihalyi's flow theory (1990) whereby engagement, skills and challenge, along with emotional and sensual engagement, lead to feelings of wellbeing. Some festivals can be seen to increase community connections, particularly in the domains of bridging capital, where people who have intersecting interests come together, and linking capital derive through the cross cutting of hierarchical and social boundaries.

The increased impact on the community contribute to community development. Community development originated in the 1960s as part of the war on poverty (Zdenek \& Walsh, 2017), and the concept has been particularly developed over the last 20 years. Phillips and Pittman (2014) describe it as a process and an outcome: the process of a community acting collectively, and the outcome is considered a development in one or several domains of a community e.g. social, cultural, economic, physical. With this in mind, community festivals can be considered as both, the process of acting collectively and development in social, cultural and economic aspects of community life (Arcodia \& Whitford, 2006; Brownett, 2018; Sholihah et al., 2019). Community development can often be a catalyst for community wellbeing, two concepts which are intimately entwined. Community wellbeing can be defined as 'the state in which the needs and desires of a community are fulfilled' (Lee et al., 2014 p. 2). This illustrates the link between community development and wellbeing.

Many festivals have volunteer programmes, which can encourage community involvement (Laing \& Mair, 2015). In return for their contribution, volunteers may receive opportunities for skill development (Jones \& Munday, 2001), along with incentives such as free tickets or food (Elstad, 2003). Festival volunteer motivations include opportunities to socialize and connect with hobbies/interests (Elstad, 2003); good citizenship (Güntert et al., 2015); and attachment to the event activity (Monga, 2006). Volunteering has been associated with improved mental and physical health (Konrath et al., 2012), happiness (Borgonovi, 2008) and increased quality of life and social support for older adults (Parkinson et al., 2010). Laura Toraldo et al. (2019) conducted an investigation among volunteers at three UK based music festivals, they found one way in which the work done by volunteers was made more meaningful was through evoking a sense communitas and creating and building social bonds. Research into increasing community involvement in festivals has shown volunteering as a good way of engaging the local community and developing a positive link between organisers and the community (Rogers \& Anastasiadou, 2011).

While some literature on volunteering in festivals exists, more research is needed to better understand the impacts of volunteering on participants, and to compare these impacts with those of contributing in other ways with the festival. Is there something specific about volunteering - being physically present for the duration of the festival and immersed in its activities which delivers benefits, or are these benefits also enjoyed by those who contribute financially and in other ways? Below, we suggest that volunteering is particularly effective as it offers a way to experience more than one of the identified'Five Ways to Wellbeing', which are discussed immediately below. 


\section{'Five Ways to Wellbeing'}

The Five Ways to Wellbeing (FWW) (Aked et al., 2008) offer a way of framing the results of this study. Contributing actively to festivals, and particularly volunteering, may offer a way to integrate the FWW into life, and hence might help to understand why such involvement with festivals obtains these apparent benefits. This is a framework which encourages individual engagement with five evidencebased actions: Connect, Be Active, Take Notice, Keep Learning and Give, that help foster wellbeing. According to Aked et al. (2008) this, in turn, helps reduce mental health problems and allows individuals to flourish. Positive psychologists describe flourishing as a state of wellbeing, providing optimal functioning, accompanied by a sense of meaning, purpose and active engagement (Ryan \& Deci, 2001). 'Connections' with people enhance and support daily life. 'Being active' and going outside, be it walking, dancing or playing, promotes positive physical and mental health. 'Taking notice' encourages people to be present and curious about one's surroundings. 'Keep learning' helps people engage with new challenges, have fun and build confidence, and 'give', whether it is giving something to self (self-care) or doing things for others such as volunteering, can be rewarding and create connections.

That the FWW might be a way to frame the results from this study occurred to one of the research team during qualitative analysis. It seemed possible that the benefits delivered by this and other festivals could be understood in terms of this framework. In the sections below, we use the FWW as a way of contextualizing the results. However, it should be acknowledged that the FWW is a pre-existing framework, and our results do not fit within it exactly. So our use of the FWW model should be understood as tentative and exploratory, rather than a set structure through which our results have to be understood. Our qualitative results - like most such results - are rich and complex, evading clear-cut conceptual formulation, rather offering a way to dialogue with the framework.

Returning to the FWW model, this has been used as a tool to: guide intervention development, evaluation, report cross-cutting findings, as well as shape policies and strategies in the UK (Aked \& Thompson, 2011; Farrier et al., 2019; Keeman et al., 2017). There has also been international engagement with the framework-the Singaporean Agency for Integrated Care and National Arts Council (2018) promote an arts and health toolkit with activities guided by the FWW. In New Zealand, a large cross-sectional survey was carried out to assess individual wellbeing and participation in the Five Ways, finding a positive association between participation and wellbeing (Mackay et al., 2019).

Encouraging individuals to adopt the FWW to promote wellbeing has been incorporated into different events and festivals, awareness-raising campaigns, galleries and museums, self-help websites and literacy tools (Aked \& Thompson, 2011). Although there is little detail on implementation or evidence on effectiveness, it has been used at all intervention levels: individual, collective/group, organization, population and strategic (Aked \& Thompson, 2011; Keeman et al., 2017; Mackay et al., 2019; Smith, 2015). Cameron et al. (2013) used the FWW framework in conjunction with an arts-based framework to evaluate the potential 
health and wellbeing benefits of participatory arts projects within communities, combining the frameworks enabled them to draw connections between the health discourse and arts discourse.

The FWW is promoted as a 'generic set of actions with wide-ranging appeal' (Aked et al., 2008 p.3), however, there is no clear direction on how the framework overcomes inequities or may be applied for those considered vulnerable. People's ability to engage with the FWW may vary according to their capacity to carry out the actions, their surroundings and the places and spaces they have access to (Phillips et al., 2015). There is also little discussion regarding levels of engagement with each action, for example it is undefined whether engaging in several actions in specific combinations correlates to higher levels of subjective wellbeing (Aked et al., 2008; Mackay et al., 2019).

The FWW framework offers a useful way to look at our results. We are not suggesting that this framework is the only possible way to interpret the results, nor are we suggesting that the framework fits every aspect of our findings unproblematically. However, the areas of overlap between our results and the framework, particularly around how subjective wellbeing, feeling good and functioning well might arise through participation in the festival, do offer a useful perspective on volunteer engagement and benefits.

\section{Broadstairs Folk Week and its Impacts for Volunteers and Contributors}

Broadstairs Folk Week (BFW) is a traditional folk music and dance festival staged annually for 55 years, although due to the impact of Covid-19, 2020 was the first year in which the festival did not run since inception. The festival operates as a registered charity whose objectives include encouraging enjoyment of English and multicultural folk dance, song and music. A week-long festival is staged with over 500 events comprising workshops, a craft fair and both informal and formal concerts. The festival attracts over 120,000 people to the host seaside town in Kent, UK. Whilst the festival has significance across the country, BFW inevitably has a greater impact on the town and community of Broadstairs. The festival has two paid employees and a small volunteer management committee. The festival receives yearly financial membership contributions from 'Friends' as well as donations from corporate sponsors in return for advertising. The management committee, 'friends' and corporate sponsors will be referred to throughout this study as 'other contributors'. The annual festival is run almost entirely by a volunteer 'Workforce' of over 200 people. Each Workforce volunteer gives at least $35 \mathrm{~h}$ of their time over the festival in one of 16 different activity teams. Throughout this study we refer to the Workforce volunteers as 'volunteers'.

The aim of this study was to examine the perceptions, motivations and wellbeing impacts for 'volunteers' and 'other contributors' to BFW. We will focus in the following on the impact on the 'volunteers', but we will discuss some of the findings from the 'other contributors' as these provide a useful contrast which underlines the benefits of volunteering as opposed to different forms of contribution. 


\section{Method}

In order to fulfil this aim, we designed a study using a mix of methods, gathering quantitative and qualitative data. We use the term 'mix of methods' rather than the more common 'mixed methods' deliberately. Acknowledging the wide variety of ways in which mixed methods as an approach is understood, a common view is that this approach utilizes quantitative and qualitative data as a way of understanding results within an overarching theoretical framework (Creswell, 2014), and as collecting different forms of data to answer the same research question. By contrast, we collected single and multi-choice questionnaire data and longer textual answers in order to get perspectives on different questions, and without assuming an over-arching theoretical perspective, but rather seeing what arose from the questions.

The research philosophy underpinning our study aligns with social constructivism. That is, we acknowledge the role played by social forces in the construction of knowledge, and that any body of knowledge cannot be considered without also considering the social contexts in which this knowledge occurs (Given, 2008). We also adhere to a post-positivist world view in which an objective world is accepted but in which such an objective world is known through myriad different experiential viewpoints (Howell, 2012).

Respondents were asked demographic and other quantitative questions as well as open-ended questions to elicit longer responses in a survey completed online. A convenience sampling method (Lavrakas, 2008) was used. The administrative office of the festival had 'opt-in' mailing lists of people who wanted to hear news connected with the festival. This list included both 'volunteers' and 'other contributors'. A link to the survey, together with explanatory text, was mailed to everyone on the list. This method had the additional benefit that anonymity could be retained, as identifying details (email and physical address, etc.), were held only by the Festival administrative office, not passed to the research team. While this sampling method offered easy access to 'volunteers' and 'other contributors', it had the drawback that the sample was biased towards particular demographics (particularly older people), which may have been exacerbated by the time taken to fill out the survey online (people who are no longer working may arguably have more time to respond to surveys). As mentioned above, anonymity was assured as no identifying details were passed from the Festival administration to the researchers. Names and emails were not collected, and additionally only the first few characters of the post code were collected (enough to identify town, but not exact location).

Data was collected in April 2018. Respondents were given a window of three weeks to respond, after which data collection closed. The survey took approximately $20 \mathrm{~min}$ to complete. In total, 525 people were invited to participate in the study by email, of these 152 completed the online questionnaire (29\%). Of these, 69 were 'volunteers' (46\%) and 83 (54\%) 'other contributors' (79 Friends of the festival, 2 members of the Management Committee and 2 Corporate Sponsors). In terms of numbers, while it would have been beneficial to survey higher numbers 
of 'volunteers' and 'other contributors', it is suggested (e.g. Cottrell \& McKenzie, 2011) that a sample size of 30 is sufficient for assessing statistical significance. Considering response rate, while a rate of $60 \%$ is considered an achievable goal in academic research (Fincham, 2008), surveys administered online are generally acknowledged to have lower response rates (Reynolds et al., 2006). In retrospect, it would have been useful to investigate to find out reasons for lack of response from people who didn't take part, but time and budget constraints ruled this out.

The same questionnaire was used for each respondent group ('volunteers' and 'other contributors'), with different wording in places and with extra questions for 'volunteers', who were asked questions to measure personal wellbeing, based on questions developed by the Office for National Statistics (ONS) (Jones \& Randall, 2018). Also included in the questionnaire for 'volunteers' were questions to measure 'festival wellbeing', adapted from the ONS personal wellbeing statements. Both questionnaires, which are available as supplementary information, gathered qualitative and quantitative data over three key areas-(1) demographics, (2) motivations and (3) perceptions of the impact of contributions and the festival itself on the individual, town and community.

Prior to data collection, the project received ethical approval from the University Faculty Ethics Panel. Areas considered included: the purposes of the study and what data would be used for, anonymity, data storage, and explicit consent.

Qualitative analysis followed Braun and Clarke's (2008) thematic approach (thematic development) and was carried out by two researchers. Initially the data was read and re-read for familiarity, 12 iterative codes (one with three sub-codes) were identified and then assigned potential themes associated with the FWW. These were then reviewed and refined. The 15 codes are as follows:

- AP (Arts Participation described):

- AP1 Describe learning or involvement in workshops

- AP2 Describe active participation in dancing or singing etc.

- AP3 Describe passive participation e.g. listening to music

- Att (attributes and assets of the town described)

- B (Personal e.g. tickets, free camping etc.)

- Bel (Belonging to or feeling part of something bigger than self)

- $\mathrm{C}$ (Connection - a sense of connecting to others through team, working together or specifically giving back)

- D (Wanting to make a difference to others or to the locale - helping described)

- E (Environment created by coming together - atmosphere, congeniality, spirit, camaraderie, kinship, community)

- Enj (Enjoyment specifically named)

- F (real or perceived opportunity for friendship/meeting others/being social/reunions)

- I (Normal life interrupted) 
- PD (personal development e.g. work experience, skills acquisition, confidence to use skills)

- WB (Wellbeing, includes happiness, feeling good, positive mental health and joy)

At the stage the codes were developed, links to the FWW were noted. The codes above were summarized in terms of the 'Five Ways', for example 'Att' as 'Take Time to Notice' and 'D' to 'Give'.

Because of the close connection between different aspects of the FWW (to 'give' often involves 'connecting' as well, for example), different relationships between our codes and the over-arching FWW themes is possible. Code 'D', for example, could be put into 'connect' rather than 'give'. To minimize bias, two researchers worked on the coding process.

For quantitative data analysis IBM SPSS 24 was used to generate descriptive statistics including frequencies, means and cross-tabulations. Both sets of results are now discussed.

\section{Results}

\section{Demographics}

The two datasets have notable and similar demographic characteristics. In terms of age, participants from both 'volunteer' and 'other contributor' datasets are age 45 or older. 49 of the $69(71.1 \%)$ 'volunteer' dataset are over 45 , and for the 'other contributors', only 4 are under 45 . Respondents are fairly equally split in terms of gender: 75 women and 72 men (5 did not answer this question). 36.2\% (25) of 'volunteers' and $78.3 \%$ (54) of 'other contributors' are retired.

\section{Geographical Distribution of Respondents}

$38.2 \%$ (58) of all respondents live locally in Broadstairs, $13.2 \%$ (20) in the local sub-region, $20.4 \%$ (31) in Kent and $27 \%$ (41) elsewhere in the UK. Thus, $73 \%$ of respondents are from Kent; this underlines that the festival is a distinctly local event, albeit one with a wider reputation and reach. This in turn may have implications for how people respond to the festival and its perceived benefits.

\section{The 'Five Ways to Wellbeing'}

Many of the findings further indicate the relevance of this framework in understanding the impact of the festival on the respondents, particularly the 'volunteers' who are more closely involved in the festival. The actions of 'be active' and 'take notice' are evident in the data to a degree but less pronounced than 'keep learning, 'connect' and 'give'. This may be a function of the nature of this (and other) festivals. The festival offers workshops where participants can learn new skills, volunteering 
can be seen as a form of giving, and the volunteering role in particular involves working in communities, establishing close connections with other people both within the workforce team and members of the public. By contrast, festivals with other types of focus e.g. sports may offer other aspects of the FWW such as 'be active'. Aked et al. (2008) developed the FWW as a framework for individual use, however, there is evidence that it relates to community e.g. strengthening community bonds (Farrier et al., 2019) and can be thought of as community development which is pronounced in the current findings.

\section{'Be Active' and 'Take Notice'}

The results from this study suggest that volunteering, particularly, offers respondents an opportunity to'be active' during their participation in the festival. The topology of the town, which rises steeply from the seafront up the main high street, and the distributed nature of the festival around the town, mean that both walking from venue to venue and dancing at events are commonplace. Qualitative comments included "Being able to dance whilst working and helping others to enjoy dancing”, "The opportunity to...take part in dances and song sessions", "all the amazing music and dancing that happens!". Although not all comments regarding 'be active' were positive, the need to walk between venues was reported as a negative by some respondents.

Respondents answers indicated that they were 'taking notice' of their surroundings and new musical experiences: they mentioned the attributes of the town itself, the town's seaside location, getting a break from routine, or enjoying the music and atmosphere. Qualitative comments included "Being by the seaside in glorious sunshine", "exceptional atmosphere", "I get to experience music that I know I love and also the chance to experience totally new bands and artistes". It should be noted here, however, that linking comments like this to the concept of 'take notice' as employed by the FWW may be seen as somewhat tenuous. No respondents mentioned increased mindfulness or higher awareness of their surroundings, however this may be unsurprising as the 'take notice' way to wellbeing has been noted as the most difficult to establish (Phillips et al., 2015). Thus this link should still be made with caution, and perhaps needs further investigation.

\section{'Keep Learning'}

Both qualitative and quantitative results supported the 'keep learning' way to wellbeing. The opportunity to 'keep learning' arose through skill development as a volunteer and workshops hosted by the festival. Respondents noted the formal and informal opportunities: "attend workshops and learn new things", "The opportunity to develop my work experience. The festival has afforded me the opportunities to stage manage, serve customers, work with children and collect funds for the festival", "has opened up new opportunities to learn about instruments, music, dance, history and culture that I wouldn't have access to without volunteering and expanded my outlook and understanding of our country, as well as the local area". 
This last statement reflects the overall cultural engagement of the respondent group where, $84.2 \%$ (128) reported visiting museums or art galleries and 129 visited a heritage site in the previous 12 months (see Table 1). That festivals can offer a way of learning is reflected in the literature, e.g. Snell (2005) argues that music teaching and learning is associated with music festivals. The role of education delivered in non-formal settings, particularly for adults, has been well documented in the literature (Bélanger, 2011).

\section{'Connect'}

The theme 'connect' emerged particularly strongly from the data, perhaps unsurprisingly given the nature of festivals as sociable events for larger groups of people. It was evident among respondents, who commented on the opportunity to meet new people, work alongside other volunteers and to actively participate as a member of the BFW community. This is supported by quantitative and qualitative findings. For example, $69.6 \%$ of 'volunteers' reported feeling motivated by meeting new people and $78.3 \%$ by the chance to participate in the BFW community, with one respondent commenting:

"The sense of community that is at the heart of the Festival. I have found that, for the most part, everyone involved pitches in, helps each other, offers support and enjoys each other's company." Others noted their increased "sense of belonging to the town and community" and the "profound sense of being part of the local community through having a role in the local folk scene". It should be kept in mind, of course, that values associated with 'connect' are likely to motivate volunteers for a festival, given that these are inherently social events,

Table 1 Cultural participation in the previous year

\begin{tabular}{llll}
\hline Participated in activity in last 12 months? & $\begin{array}{l}\text { Total volunteers } \\
\text { and contributors } \\
(\mathrm{n}=152)\end{array}$ & $\begin{array}{l}\text { Volunteers } \\
(\mathrm{n}=69)\end{array}$ & $\begin{array}{l}\text { Other Contributors } \\
(\mathrm{n}=83)\end{array}$ \\
\hline Attended festival other than folk week & 93 & 47 & 46 \\
& $(61.2 \%)$ & $(68.1 \%)$ & $(55.4 \%)$ \\
*Visited museum or art gallery & 128 & 57 & 71 \\
& $(84.2 \%)$ & $(82.6 \%)$ & $(85.5 \%)$ \\
*Attended arts event & 88 & 38 & 50 \\
& $(57.9 \%)$ & $(55.1 \%)$ & $(60.2 \%)$ \\
*Participated in arts activity & 51 & 22 & 29 \\
& $(33.6 \%)$ & $(31.9 \%)$ & $(34.9 \%)$ \\
*Visited heritage site (castle, cathedral, & 129 & 56 & 73 \\
important landmark) & $(84.9 \%)$ & $(81.2 \%)$ & $(88.0 \%)$ \\
$*$ Visited a library & 95 & 41 & 54 \\
& $(62.5 \%)$ & $(59.4 \%)$ & $(65.1 \%)$ \\
Participated in a sporting activity & 54 & 27 & 27 \\
& $(35.5 \%)$ & $(39.1 \%)$ & $(32.5 \%)$ \\
\hline
\end{tabular}

(* denotes the activities which may formally be associated with Keep Learning) 
so these results can also be read as "volunteers" expectations about the festival being fulfilled.

'Volunteers' were notably more positive about connection than 'other contributors'. Q7, for example, asked about the impact of the respondent's personal contribution to BFW on opportunities to make new friends, and the results for each group are summarised below in Table 2. An independent sample t-test was conducted and for Q7 ( $\mathrm{p}=0.00$ with equal variances assumed) the difference between 'volunteers' and 'other contributors' is statistically significant (data available upon request).

Differences between respondents living in Broadstairs and those living elsewhere for the 'impact' questions also seem to illustrate the concept of 'connect' as a way to wellbeing. That is, the results suggest that respondents living in the town feel more connected to the festival and community of Broadstairs, and rate social, economic and cultural impacts as more important (Q7-q10, Q20-Q22). This is illustrated by Table 3, below. An independent sample t-test was conducted and the difference between those living in Broadstairs and those living elsewhere for Q9 ( $p=0.003$ with equal variances not assumed) and Q10 ( $p=0.012$ with equal variances assumed) shows statistical significance (data available upon request).

These overall findings for the theme 'connect' are supported by qualitative comments as follows:

- "Meeting lovely people. Being part of a team. Helping Broadstairs traders"

- "To meet like-minded people, to further the aims of folk week, to keep folk tradition alive."

- "Feeling of involvement in something that I have enjoyed as a customer for many years. Working with a lovely group of people and the social aspect of the work. A feeling of paying back into something that I value highly."

- "As new residents in 2013 it helped us to integrate with the local community."

- "I have met a lot of great people through my involvement with folk week. I volunteered for the first time at the time that I moved to Broadstairs, and thus I met a lot of people who have involvement with the folk music scene in Thanet. Folk Week would not happen without the efforts of hundreds of people, and there is satisfaction in being one of those who "make it happen"."

The FWW concept of 'connect' is that it is very broad, covering connecting with other people as individuals and a sense of belonging at the heart of the community. Both of these senses of 'connect' are mentioned by respondents, as above. However, this raises a question of the utility of such a broad concept as utilised within the FWW and perhaps should be approached with caution.

\section{'Give'}

The data suggests that to 'give' is important to respondents, in terms of a way of understanding what they are doing at the festival, with both qualitative and quantitative findings suggesting that the contributions made have perceived benefits for both local and folk communities. The act of volunteering or contributing to the festival 


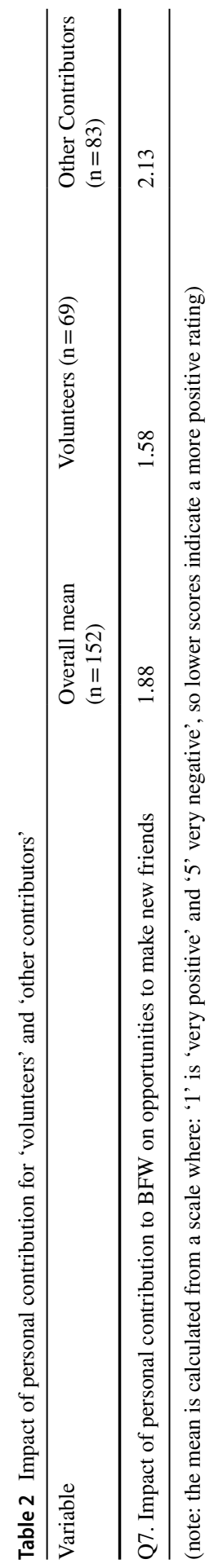




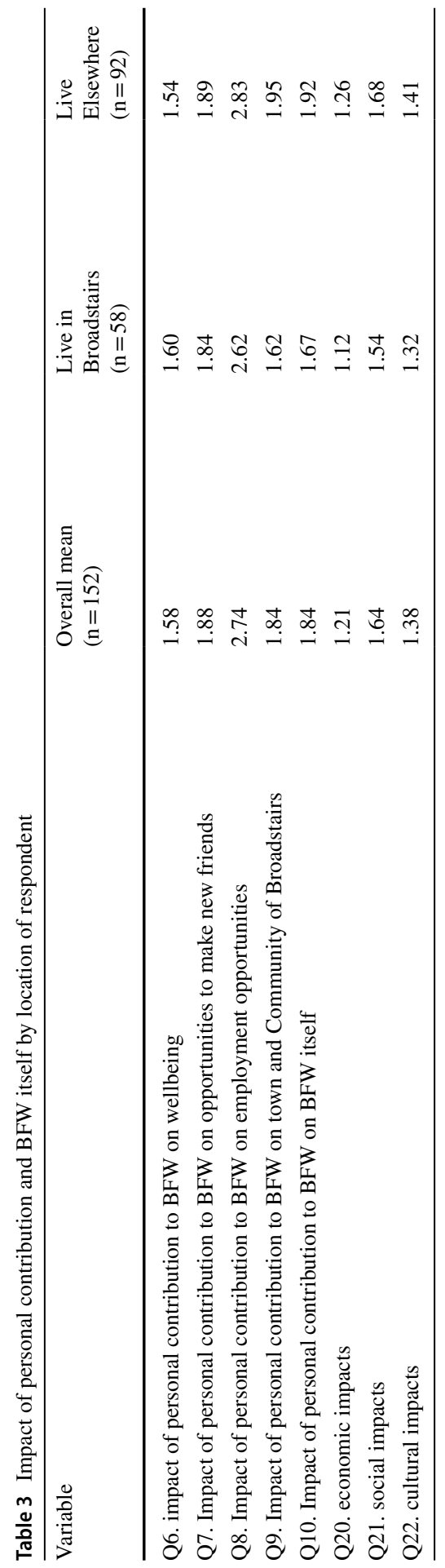


are both acts of 'giving' and can be seen as contributing to community development outcomes. The importance of 'giving' as a motivator and frame for understanding is further illustrated by Table 4 .

These findings are reinforced by the high levels of perceived wellbeing reflected in the responses to the ONS national survey questions included in the questionnaire for volunteers. 'Volunteers' rate the impact of their giving more positively than do 'other contributors' although this is not surprising considering the number of hours they contribute during the event. This also illustrates the enhanced wellbeing individuals experience when they consider the wider overarching impact of their contribution on their community or communities.

In order to identify motivations for volunteering 'volunteer' respondents were presented with 12 statements and asked to select the most important reason, the statements 'to contribute to the festival', 'to enjoy the festival' and 'to contribute to the local community' were the most frequently selected. Across the whole group of respondents $(\mathrm{N}=152)$, 'volunteers' and 'other contributors', the level of commitment to contributing to the festival again was high, with $89 \%$ reporting it was 'Very Likely' or 'Likely' that they would contribute to the festival next year. $80 \%$ of 'volunteers' and $96 \%$ of 'other contributors' said they were 'Very Likely' or 'Likely' to contribute to BFW next year.'Volunteers' were asked what it is that is most likely to make them volunteer again, below are some of responses:

- "Sense of community within the workforce. Being able to contribute to the successful running of such an important event to the town. Camping with friends"

- "For me, it is the sense of community and purpose that I get from volunteering. The time I get to spend with my friends and meeting new people while helping to put on such a varied and fantastic event is so satisfying for me and makes me very happy."

- "The volunteers make it that extra special, and the friends you make during the festival. I was made to feel welcome almost immediately during Folk week 2017."

- "The fact that every year I enjoy the week so much is what makes me want to sign up again. That is down to a combination of things - the event, the people I work with/socialise with, the pleasure of being at the seaside in a lovely little town like Broadstairs. Also, it is one of the few weeks of the year when I get any exercise to speak of!"

Table 4 Impact of personal contribution for volunteer and contributor data sets

\begin{tabular}{llll}
\hline Variable & $\begin{array}{l}\text { Overall mean } \\
(\mathrm{n}=152)\end{array}$ & $\begin{array}{l}\text { Volunteers' } \\
(\mathrm{n}=69)\end{array}$ & $\begin{array}{l}\text { Other } \\
\text { Contribu- } \\
\text { tors } \\
(\mathrm{n}=83)\end{array}$ \\
\hline $\begin{array}{l}\text { Q9 Impact of personal contribution to BFW on town and } \\
\text { Community of Broadstairs }\end{array}$ & 1.84 & 1.81 & 1.86 \\
Q10 Impact of personal contribution to BFW on BFW itself & 1.84 & 1.68 & 1.96 \\
\hline
\end{tabular}


- "The enjoyment and sense of being part of something amazing, that makes a difference to the experience of others. The festival is not just the events but all the people, watching them enjoy themselves and being part of the community and all the friends I have made, are the reason, I will do it again”

\section{Discussion}

The FWW framework provides a useful way to understand the benefits of volunteering or contributing to BFW on subjective wellbeing. The evidence suggests that volunteering at an arts and cultural festival offers a way to engage in the FWW as volunteers work with others in teams, are physically active, enjoy music events and other activities, actively engage in learning activities, and feel part of a wider community. Thus, our respondents appear to experience subjective wellbeing, enhanced by their voluntary contributions to the festival. This concurs with Cameron et al. (2013, p. 55) who suggest the five actions from the framework 'correspond closely to behaviours that can emerge in well-designed participatory arts projects'. Farrier et al. (2019) also note the usefulness and flexibility of the FWW framework in being applied to a range of diverse projects, they noted the presence of each action across case studies despite no explicit reference.

As the findings suggest, the closer respondents live to the host town, the more marked the perceived impact of contributing to the festival. This reinforces the idea that BFW is a strongly local festival. Additionally, local respondents give a higher average rating for the impact of BFW on employment opportunities, making new friends, community, the economy and, on social and cultural impacts, all contributing towards community wellbeing. The festival itself can be seen as a form of community development.-BFW notably contributes to social, economic and cultural aspects of community life which helps actualise community wellbeing.

The links between the FWW and community have been previously been noted (e.g. Farrier et al., 2019). If the perceived impacts of contributing to the festival are greater if respondents live closer to the festival location, it is interesting to consider the mechanism for this. One possibility is that the kind of multi-faceted approach to wellbeing encompassed by the FWW facilitates the cementing of social bonds and sense of connectivity through an increase in social capital. Social capital, a concept originating with Putnam (1993), can be used to understand how festivals promote wellbeing; Brownett (2018) describes a process whereby improved relationships can lead to an increased sense of trust and reciprocity, in turn leading to an increased sense of community and awareness of available opportunities and resources, which consequently, helps facilitate community wellbeing and positive community development.

One interesting trend in the data is the age and location of participants: most survey participants were over 45 and lived in or near the festival town. Perhaps this group either feel more connected or have more time available to participate in research. Although it is perhaps unsurprising that those who chose to respond, were predominantly local people. Indeed, the findings suggest that the festival is embedded in the life of the local community and the high motivation for volunteering 
likely reflects the significance of the festival, particularly (from these findings) to older age groups.

As discussed above, 'giving' can be interpreted as an act for self or others. It might be predicted, therefore, that volunteers, as their role by definition involves 'giving', would rate questions connected to perceptions of wellbeing and social outcomes more positively than contributors. Volunteers arguably give more of themselves: their energy and their time than other types of contributor. These predictions are supported by the results. Table 4, above, shows that 'volunteers' rate the impact of their contribution to BFW on the community of Broadstairs and BFW itself more highly than do the 'other contributors' in this study.

Our study has shown that volunteering may support a connection to other volunteers, a folk community and the local community. Kahana et al. (2013) argue that through volunteering, older people demonstrate prosocial behaviours, behaviours that benefit others or society as a whole, and attitudes resulting in meaningful connections, civic engagement, enhanced subjective wellbeing and life satisfaction. They argue that this is important for mental health and flourishing in later life.

It is however acknowledged, that wellbeing is complex and multifaceted, and as such encompasses broad physical, mental, environmental and social aspects. Although the FWW framework is a way to understand these results, and, given its widespread use in community contexts, a way of potential dissemination, it is a simplification of a set of relationships which are complex and nuanced. Additionally, there are some failings with the model. It could be argued that the focus is on the individual to take steps to improve their own wellbeing, rather than on the socioeconomic determinants that also need to be taken into account. The FWW model is one which focuses on individual actions and responsibility. But such individualist perspectives, as Fisher (2019 p.2) states, offer "biomedical and behavioural approaches to health; and thus conceptualise wellbeing purely in terms of individual behavior and construct solutions accordingly.... rather than to address salient social or economic factors". Our study was not singularly able to disentangle these facets or specify a causal mechanism.

\section{Conclusion}

In conclusion the actions of 'connect' and 'give' from the FWW appear to be important motivating factors for people to volunteer and contribute to a local arts and cultural festival. The perceived benefits are in the opportunity to be part of a community and to contribute positively to the local town.

These results have demonstrated that community members who play a participatory role e.g. volunteering in a community festival have the opportunity, through engaging with the FWW, to develop their connectivity with others and to contribute to their geographical community and the festival community, both creating social capital and contributing to individual and collective wellbeing. An implication drawn from this research, therefore, is that the FWW may be used as a framework to guide community festivals which draws on the local community as a volunteer base, in turn, increasing their effectivity within the societal structures of that community. 
It has been noted that the FWW is promoted as a tool for individual use and shortcomings have been documented, it is therefore recommended that more research is done to develop the FWW as a potential framework for community development purposes.

Our participants might have initially been more likely to volunteer because of a sense of subjective wellbeing, however festival volunteering further improves subjective wellbeing, through engagement with the FWW. Moreover, participants in this study report experiencing additional personal benefits, including sense of connection and reciprocity, which might further contribute to a sense of personal wellbeing. Along with access to wider resources, potentially including those beneficial for good health, contribution to the festival is important in developing a sense of connection to community and belonging which in turn may foster social capital. This may be beneficial to the public health agenda for ageing well, flourishing and reducing isolation. However, it's important to bear in mind that the FWW model takes an individualistic perspective, and arguably fails to accommodate socio-economic perspectives. BFW's demographic within this study is predominantly older and wealthier than average, and more needs to be done to ensure that the apparent benefits of participatory music and festivals can be accessed by all demographic groups.

Supplementary Information The online version contains supplementary material available at https://doi. org/10.1007/s42413-021-00154-2.

Data Availability Available upon request.

Code Availability Not Applicable.

\section{Declarations}

Research Involving Human Participants and/or Animals Prior to commencing the research, university ethical approval was obtained.

Informed Consent All human participants provided written informed consent.

Conflicts of Interest The authors declare that they have no conflicts of interest.

\section{References}

Agency for Integrated Care and National Arts Council. (2018). Sparks! Art for wellness toolkit for the community care sector. Agency for Integrated Care.

Aked, J., Marks, N., Cordon, C. and Thompson, S. (2008). Five ways to wellbeing: A report presented to the Foresight Project on communicating the evidence base for improving people's well-being, New Economics Foundation. Retrieved from https://b.3cdn.net/nefoundation/8984c5089d5c228 5ee_t4m6bhqq5.pdf

Aked, J., \& Thompson, S. (2011). Five ways to wellbeing: New applications, new ways of thinking. New Economics Foundation.

Arcodia, C., \& Whitford, M. (2006). Festival attendance and the development of social capital. Journal of Convention and Event Tourism, 8(2), 1-18. 
Arts Council England. (2018). Arts council-national lottery project grants: Festivals and carnival arts projects. Arts Council England. Retrieved from https://www.artscouncil.org.uk/sites/default/files/ download-file/Information_sheets_Festivals_carnival_arts_Project_grants200418.pdf

Ballantyne, J., Ballantyne, R., \& Packer, J. (2004). Designing and managing music festival experiences to enhance attendees' psychological and social benefits. Musicae Scientiae, 18(1), 65-83.

Bélanger, P. (2011). Theories in adult learning and education. Verlag Barbara Budrich. https://doi.org/ $10.2307 /$ j.ctvbkjx 77

Biaett, V. (2015). Organic festivity: A missing ingredient of community festival. In Jepson, A., and Clarke, A. (eds) Exploring community festivals and events (pp. 17 - 30). Routledge.

Biaett, V. (2017). Festivity, play well-being...Historical and rhetorical relationships: Implications for communities. In Phillips, R. and Wong, C. (eds) Handbook of community well-being research (pp. 189 - 198). Springer.

Biaett, V. (2019). Festivity and attendee experience: a confessional tale of discovery. In Mair, J. (ed.) The Routledge handbook of festivals. Routledge

Borgonovi, F. (2008). Doing well by doing good: The relationship between formal volunteering and selfreported health and happiness. Social Science and Medicine, 66(11), 2321-2334.

Braun, V., \& Clarke, V. (2008). Using thematic analysis in psychology. Qualitative Research in Psychology, 3(2), 77-10.

Brownett, T. (2018). Social capital and participation: The role of community arts festivals for generating wellbeing. Journal of Applied Arts and Health, 9(1), 71-84.

Brownett, T. and Evans, O. (2020). Finding common ground: The conception of community arts festivals as spaces for placemaking. Health \& Place, 61, p.102254.

Cameron, M., Crane, N., Ings, R., \& Taylor, K. (2013). Promoting well-being through creativity: How arts and public health can learn from each other. Perspectives in Public Health, 133(1), 52-59.

Cottrell, R., \& McKenzie, J. (2011). Health promotion and education research methods (2nd ed.). Jones \& Bartlett Learning.

Creswell, J. W. (2014). Research design: Qualitative, quantitative and mixed method approaches. Sage publications.

Csikszentmihalyi, M. (1990). Flow: The psychology of optimal experience (Vol. 1990). Harper \& Row.

Elstad, B. (2003). Continuance commitment and reasons to quit: A study of volunteers at a jazz festival. Event Management, 8(2), 99-108.

Falassi, A. (1987). Time out of time: Essays on the festival. University of New Mexico.

Farrier, A., Dooris, M., \& Froggett, L. (2019). Five ways to wellbeing: Holistic narratives of public health programme participants. Global Health Promotion, 26(3), 71-79.

Fincham, J. E. (2008). Response rates and responsiveness for surveys, standards and the journal. Americal Journal of Pharmaceutical Education, 72(2), 43.

Fisher, M. (2019). A theory of public wellbeing. BMC Public Health, 19(1), 1-12.

Getz, D. (1991). Festivals, special events, and tourism. Van Nostrand Reinhold.

Getz, D. (1997). Event management and event tourism. Cognizant Communication Corp.

Given, L. M. (2008) The SAGE encyclopedia of qualitative research methods Vol 1, SAGE

Gorman-Murray, A. (2009). What's the meaning of chillout? Rural/urban difference and the cultural significance of Australia's largest rural GLBTQ festival. Rural Society, 19(1), 71-86.

Güntert, S. T., Neufeind, M., \& Wehner, T. (2015). Motives for event volunteering: Extending the functional approach. Nonprofit and Voluntary Sector Quarterly, 44(4), 686-707.

Hassanli, N., Walters, T., \& Friedmann, R. (2020). Can cultural festivals function as counterspaces for migrants and refugees? The case of the New Beginnings Festival in Sydney. Leisure Studies, 39(2), $165-180$.

Howell, K. E. (2012). An introduction to the philosophy of methodology. SAGE Publications.

Jensen, A. (2013). Beyond the borders: The use of art participation for the promotion of health and wellbeing in Britain and Denmark. Arts and Health, 5(3), 204-215.

Jones, C. and Munday, M. (2001). Tourism and local economic development: Three case studies. European Regional Science Association 41st Annual Meeting European Regional Development Issues in the New Millennium and their impact on economic Policy, in Zagreb, Croatia, August 2001. Retrieved from http://orca.cf.ac.uk/44685/

Jones, R. and Randall, C. (2018). Measuring national wellbeing: Quality of life in the UK. Office for National Statistics 2018. Retrieved from https://www.ons.gov.uk/releases/measuringnationalwel lbeinglifeintheukapril2018 
Kahana, E., Bhatta, T., Lovegreen, L. D., Kahana, B., \& Midlarsky, E. (2013). Altruism, helping and volunteering, pathways to wellbeing in late life. Journal of Aging and Health, 25(1), 159-187.

Keeman, A, Näswall, K., Malinen, S. and Kuntz, J. (2017). Employee wellbeing: Evaluating a wellbeing intervention in two settings. Frontier Psychology, 8 (505).

Konrath, S., Fuhrel-Forbis, A., Lou, A., \& Brown, S. (2012). Motives for volunteering are associated with mortality risk in older adults. Health Psychology, 31(1), 87-96.

Laing, J., \& Mair, J. (2015). Music festivals and social inclusion - the festival organizers' perspective. Leisure Sciences, 37(3), 252-268.

Laura Toraldo, M., Islam, G., \& Mangia, G. (2019). Serving time: Volunteer work, liminality and the uses of meaningfulness at music festivals. Journal of Management Studies, 56(3), 617-654.

Lavrakas, P. J. (2008). Encyclopedia of survey research methods (Vols 1-10). CAL Sage Publications.

Lee, S.J., Kim, Y. and Phillips, R. (2014). Community well-being and community development: Conceptions and applications. Springer.

Li, Y., \& Wood, E. H. (2014). Music festival motivation in China: Free the mind. Journal of Leisure Studies, 35(3), 332-351.

Mackay, L., Egli, V., Booker, L.-J., \& Prendergast, K. (2019). New Zealand's engagement with the five ways to wellbeing: Evidence from a large cross-sectional survey. Kōtuitui, 14(2), 230-244.

Matarasso, F. (1996). Northern lights: The social impact of the Fèisean (Gaelic Festivals). Stroud, UK: Comedia. https://www.feisean.org/wp-content/uploads/NorthernLights.pdf

McQueen-Thomson, D., James, P. and Ziguras, C. (2004). Promoting mental health and wellbeing through community and cultural development: A review of literature focusing on community festivals and celebrations. The Globalism Institute.

Monga, M. (2006). Measuring motivation to volunteer for special events. Event Management, 10(1), 47-61.

Parkinson, L., Warburton, J., Sibbritt, D., \& Byles, J. (2010). Volunteering and older women: Psychological and health predictors of participation. Aging and Mental Health, 14(8), 917-927.

Phillips, R., \& Pittman, R. (2014). An introduction to community development (2nd ed.). Routledge.

Phillips, R., Evans, B., \& Muirhead, S. (2015). Curiosity, place and wellbeing: Encouraging place-specific curiosity as a 'way to wellbeing.' Environmental Planning A, 47(11), 2339-2354.

Putnam, R. D. (1993). The prosperous community; Social capital and public life. The American Prospect, $13,35-42$.

Reynolds, R.A., Woods, R. and Baker, J.D. (2006). Handbook of research on electronic surveys and measurements (eds). Igi Global.

Rogers, P., \& Anastasiadou, C. (2011). Community involvement in festivals: Exploring ways of increasing local participation. Event Management, 15(4), 387-399.

Royal Society for Public Health. (2013). Arts, health and wellbeing beyond the millennium: How far have we come and where do we want to go?', Royal Society for Public Health. Retrieved from https:// www.rsph.org.uk/resourceLibrary/arts-health-and-wellbeing-beyond-the-millennium-how-far-havewe-come-and-where-do-we-want-to-go-.html.

Ryan, R. M., \& Deci, E. L. (2001). On happiness and human potentials: A review of research on hedonic and eudaimonic well-being. Annual Review of Psychology, 52(1), 141-156.

Sholihah, A. B., Agustiananda, P. A., Junanah, J., \& Setiawan, W. (2019). Traditional architecture: The role of traditional festival in islamic historic district to achieve local community wellbeing'. Journal of Design and Built Environment, 19(3), 13-23.

Smith, K. (2015). Evaluation of five ways to wellbeing: Evaluation of pilot roll-out of five ways group engagement and brief intervention products and training. University of Hertfordshire.

Snell, K. (2005). Music education through popular music festivals: A study of the OM music festival in Ontario, Canada. Action, Criticism and Theory for Music Education, 4(2), 2-25.

Yoo, I. Y., Lee, T. J., \& Lee, C.-K. (2013). Effect of health and wellness values on festival visit motivation. Asia Pacific Journal Tourism Research, 20(2), 152-170.

Zdenek, R. O., \& Walsh, D. (2017). Navigating community development: Harnessing comparative advantages to create strategic partnerships (pp. 21-52). Springer Nature.

Publisher's Note Springer Nature remains neutral with regard to jurisdictional claims in published maps and institutional affiliations. 


\section{Authors and Affiliations}

\section{E. Coren ${ }^{1}$ (D) J. Phillips ${ }^{2}$ D . J. Moore ${ }^{1}$ D $\cdot$ T. Brownett $^{3} \cdot$ L. Whitfield $^{2}$}

J. Phillips

jes.phillips@canterbury.ac.uk

J. Moore

julia.moore@canterbury.ac.uk

T. Brownett

tristi.brownett@canterbury.ac.uk

L. Whitfield

laura.whitfield@gmail.com

1 Canterbury Christ Church University, Sidney De Haan Centre for Arts and Health, Faculty of Medicine, Health and Social Care, North Holmes Road, Canterbury, Kent CT1 1QU, England

2 Formerly Sidney De Haan Centre for Arts and Health, Faculty of Medicine, Health and Social Care, Canterbury Christ Church University, North Holmes Road, Canterbury, Kent CT1 1QU, England

3 School of Allied and Public Health Professions, Canterbury Christ Church University, North Holmes Road, Canterbury, Kent CT1 1QU, England 